\title{
Evidence of clonal propagation in Cryptomeria japonica D. Don distributed on Pacific Ocean side in Japan
}

\author{
Güliz Doğan ${ }^{1,2}$, Takumi Tadama ${ }^{1}$, Hiroki Kohama ${ }^{3}$, Asako Matsumoto ${ }^{4}$, Yoshinari Moriguchi ${ }^{1}$ \\ ${ }^{1}$ Graduate School of Science and Technology, Niigata University, 8050, Igarashi 2-Nocho, Nishi-ku Niigata 950-2181, \\ Japan. \\ 2 Present address: Ankara University, Faculty of Science, Department of Biology, Besevler/Ankara, Turkey. \\ ${ }^{3}$ Faculty of Agriculture, Niigata University, 8050, Igarashi 2-Nocho, Nishi-ku Niigata 950-2181, Japan. \\ ${ }^{4}$ Department of Forest Genetics, Forestry and Forest Products Research Institute, 1 Matsunosato, Tsukuba, Ibaraki \\ 305-8687, Japan
}

Corresponding author: Yoshinari Moriguchi, E-mail: chimori@agr.niigata-u.ac.jp

\begin{abstract}
Cryptomeria japonica is distributed on the Pacific Ocean side and reproduces only by seedling; however, C. japonica var. radicans is distributed on the Japan Sea side and reproduces by both seedling and layering. Until now, there has been no report that $C$. japonica on the Pacific Ocean side regenerates by layering. In this study, the regeneration system of $C$. japonica in a national forest of Miyagi Prefecture Ishinomaki City was investigated using DNA analysis. C. japonica growing in the study plot was divided into seven genets and 40 single ramets, clearly suggesting that $C$. japonica at this site regenerates not only by seedling, but also by layering. The strong winds and low temperature appear to be key factors in layering reproduction at this site.
\end{abstract}

Keywords: sugi, C. japonica var. radicans, SSR, microsatellite, clone reproduction

\section{Introduction}

Cryptomeria japonica D. Don (Sugi) is an allogamous and windpollinated coniferous species endemic to Japan (Tsumura, 2011). Natural forests are discontinuous and restricted to small areas ranging from Aomori Prefecture $\left(40^{\circ} 42^{\prime} \mathrm{N}\right)$ in the north to Yaku Island $\left(30^{\circ} 15^{\prime} \mathrm{N}\right)$ in the south. The altitudinal distribution ranges from $0 \mathrm{~m}$ in Wakayama Prefecture to 2,070 $\mathrm{m}$ in Toyama Prefecture (Maeda, 1983; Taira, 1985). This species has adapted to a wide range of environmental conditions and is the most important forestry species in Japan. Variations among the natural forests of $C$. japonica throughout Japan were investigated using diterpene components (Yasue et al., 1987), which suggested two varieties, known locally as ura-sugi (C. japonica var. radicans, growing on the Japan Sea side) and omote-sugi (C. japonica, growing on the Pacific Ocean side) (Yamazaki et al., 1995). Regarding the morphological features of leaves, there is no clear difference between C. japonica and C. japonica var. radicans (Tohyama, 1960). In contrast, there is a clear difference in their reproduction systems, i.e., C. japonica on the Pacific Ocean side reproduces only by seedling, but $C$. japonica var. radicans on the Japan sea side reproduces both by seedling and layering (Yamazaki et al., 1995, Ohashi et al., 2015). Layering generally occurs when a sprout touch to the ground by snow pressure. In the mountainous, high-altitude regions on the Japan Sea side, C. japonica var. radicans reproduces only by layering because it is not possible to regenerate through seedlings (Taira et al., 1997; Moriguchi et al., 2001). Kimura et al. (2013) reported the clonal propagation of 13 natural populations ( 3 populations on the Pacific Ocean side and 10 
populations on the Japan Sea side), and confirmed that layering is a peculiar characteristic of populations on the Japan Sea side (i.e., C. japonica var. radicans). For a significant period, this was the adopted theory.

Taira (2011) recently described the possibility of clonal propagation of $C$. japonica in the Ishinomaki population based on its morphological features (curved stem and/or sprouts from the stem). This population is located on the Pacific Ocean side, being classified into the group of the Pacific Ocean side by Yasue et al. (1987). In this study, we analyzed the clonal structure in the Ishinomaki $C$. japonica population by using simple sequence repeat (SSR) markers, and investigated whether $C$. japonica can reproduce by layering.

\section{Materials and Methods}

\section{Study plot}

A study plot ( $36 \times 36 \mathrm{~m}$ ) was established at Miyagi Prefecture, Ishinomaki City at a latitude-longitude of N38 19.026, E141 27.953. C. japonica was dominant in the canopy. Pinus densiflora, Abies firma, Chamaecyparis pisifera, Aesculus turbinate, and Acer palmatum were also present in this plot. All C. japonica ramets over $5 \mathrm{~cm}$ in diameter at breast height (DBH) were mapped, and the measured $\mathrm{DBH}$, tree height, and needle tissues were collected for DNA analysis. Root connections and large curved stems (Figure 1) were carefully checked. The basal area (BA) was calculated based on the DBH.

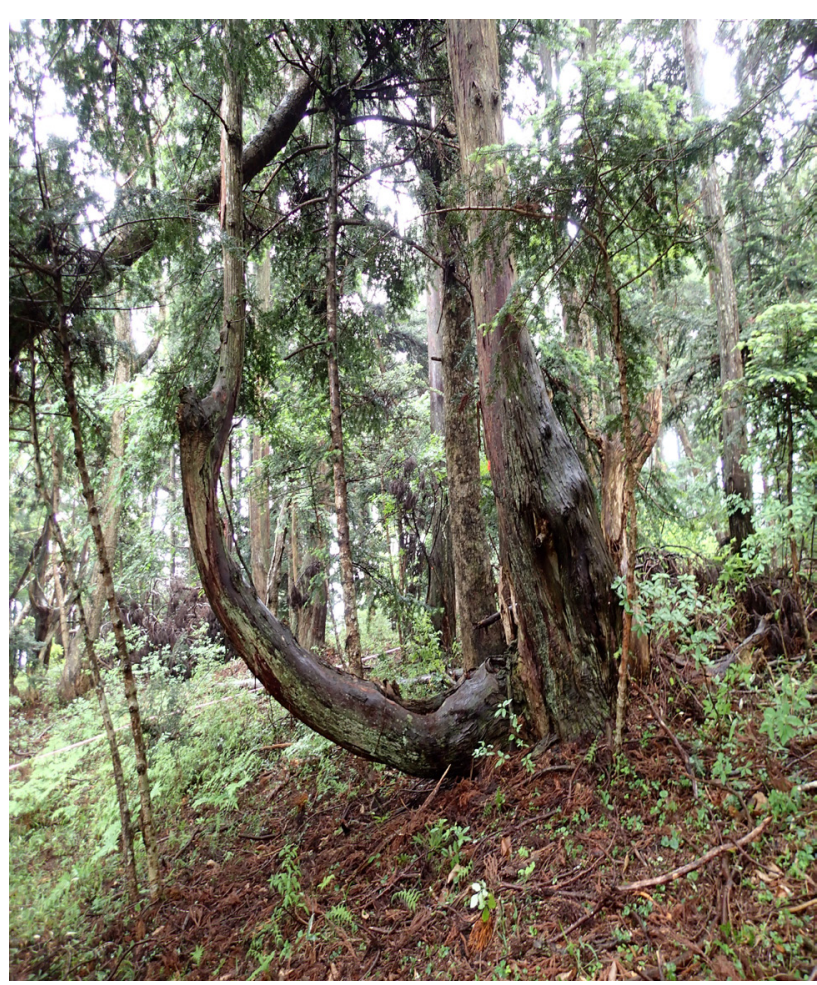

Figure 1

A Cryptomeria japonica tree in the study plot with a large curved stem.

\section{Environmental factors}

We assessed the wind speed, snow depth, and slope angle at the study plot. The snow depth was calculated from the 1-km mesh snowfall data over a period of 30 years (from 1971 to 2000), which were obtained using the program provided with the Mesh Climatic Data of Japan, published by the Japan Meteorological Agency (2000), to compare the data to those reported by Kimura et al. (2013). The wind data of Ishinomaki, Hamamatsu (Shizuoka Prefecture), Kaiyo (Tokushima Prefecture), and Kito (Tokushima Prefecture) (the three areas other than Ishinomaki used as study sites of $C$. japonica described by Kimura et al., 2013) were calculated from the data over a period of approximately 8 years (from 2009 to 2016), which were collected from the Japan Meteorological Agency. The slope angle was measured using a laser telemeter (TruPulse 200, Laser Technology, Inc., Centennial, CO, USA).

\section{DNA analysis}

Total DNA was extracted from the young needle tissue of each ramet using a modified cetyltrimethyl ammonium bromide method (Tsumura et al., 1995). We determined the genotypes of all ramets using the eight highly polymorphic genomic SSR markers described by Kimura et al. (2013) and used for clone identification (CS1525, CS1579, CS1219, CJS0520, CS1364, CS2169, CJG0077, and CJS0333; Moriguchi et al., 2003; Tani et al., 2004). PCR amplifications were performed in 6- $\mu \mathrm{L}$ reaction volumes containing $5 \mathrm{ng}$ genomic DNA, $3 \mu \mathrm{L}$ of $2 \times$ QIAGEN Multiplex Master Mix (QIAGEN, Hilden, Germany), and $2 \mu \mathrm{M}$ of each primer (forward primer labelled with dye in each primer pair). Amplifications were performed on a Takara PCR Thermal Cycler (Takara, Tokyo, Japan) under the following conditions: initial denaturation for $15 \mathrm{~min}$ at $95^{\circ} \mathrm{C}$, followed by 30 cycles of denaturation for $30 \mathrm{~s}$ at $94^{\circ} \mathrm{C}$, annealing for $90 \mathrm{~s}$ at $57^{\circ} \mathrm{C}$, extension for $60 \mathrm{~s}$ at $72^{\circ} \mathrm{C}$, and a final extension for $60 \mathrm{~min}$ at $60^{\circ} \mathrm{C}$. PCR products and the DNA size marker (LIZ600; Life Technologies, Foster City, CA, USA) were separated by capillary electrophoresis on an ABI 3130 Genetic Analyzer (Applied Biosystems, Tokyo, Japan). DNA fragments were detected using GeneMarker software (ver. 2.4.0; SoftGenetics, State College, PA, USA).

\section{Statistical analysis}

Differences in wind strength among the four populations were examined by the Tukey-Kramer test. Statistical analysis was performed using R software (ver. 3.0.3; R Development Core Team, Vienna, Austria).

\section{Results and Discussion}

The BA of $C$. japonica had a biased distribution due to its smaller size; however, there were some large ramets with a BA of over $10,000 \mathrm{~cm}^{2}$ (Figure 2). The wind strength at Ishinomaki was significantly stronger than that at the other three sites on the Pacific Ocean side (Figure 3). The strong wind increased the possibility of fallen trees. In fact, there were some fallen trees in the study plot, which improved the light conditions, thus 
exerting a positive effect on the establishment of $C$. japonica seedlings.

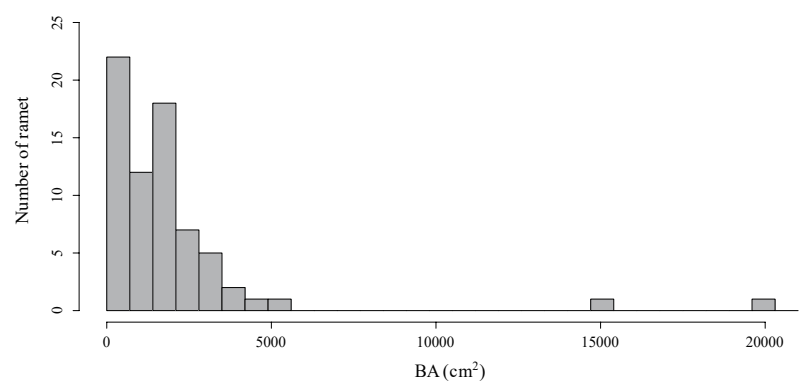

Figure 2

Basal area (BA) of $C$. japonica distributed in the study plot.

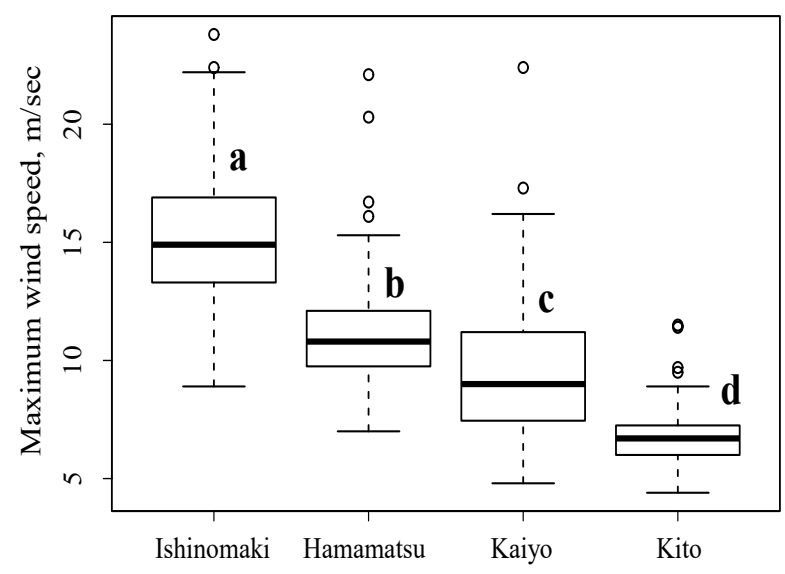

Figure 3

Comparison of wind data for four areas on the Pacific Ocean side of Japan. Three of the areas, excluding Ishinomaki, were used as study sites by Kimura et al. (2013).

There were 61 ramets in the study plot, four ramets of which had a large curved stem (Figure 4). According to SSR analysis, $C$. japonica growing in the study plot was divided into seven genets and 40 single ramets. Most of genets ( $B, C, E, F$ and $G$ ) were spread flat area. The largest genet consisted of five ramets, and the smallest genet consisted of two ramets. These results clearly show that $C$. japonica in the Ishinomaki population, which is located on the Pacific Ocean side, regenerates not only by seedling, but also by layering. Taira (1994) classified the layering of $C$. japonica into two major types: sprout-layering and seedling-layering. Sprout-layering is derived from sprouts with the stem touching the ground, and seedling-layering is derived from seedlings creeping on the ground. In the Ishinomaki population, both layering types are possible.

The average snow depth over the 30-year period in Ishinomaki was only $7 \mathrm{~cm}$, which is typical for the Pacific Ocean side (average snow depth of Hamamatsu, Kaiyo, and Kito = 1, 3, and $6 \mathrm{~cm}$, respectively (Kimura et al., 2013)). Kimura et al. (2013) detected layering in various populations on the Japan Sea side (associated with C. japonica var. radicans; average snow depth $=26-132 \mathrm{~cm}$ ). Although snow pressure is one of the most

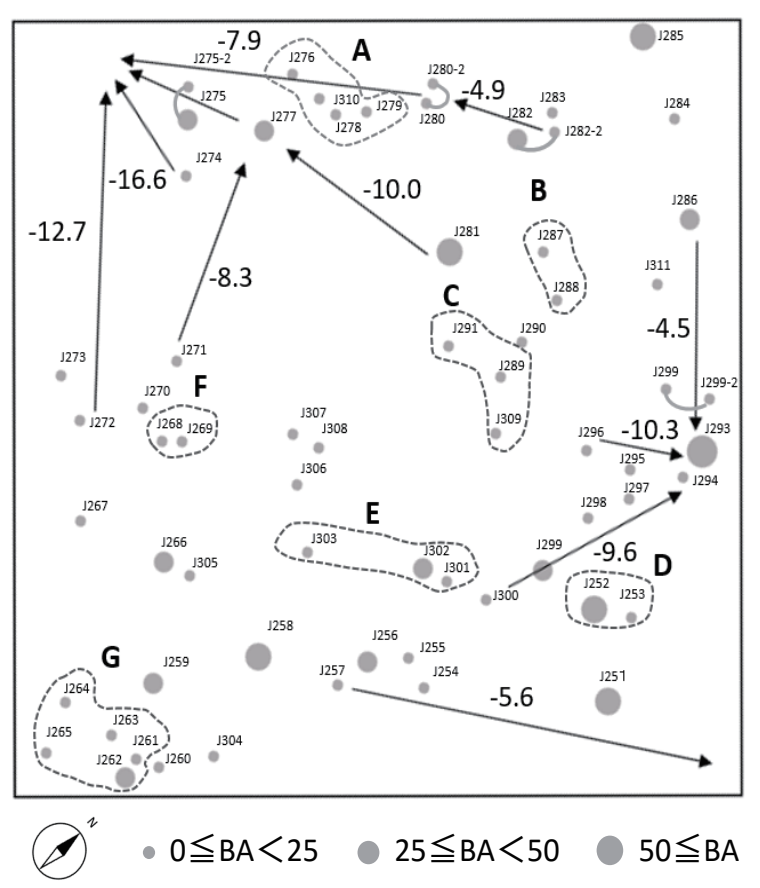

Figure 4

Location of $C$. japonica in the study plot. Circles indicate the $B A$. The sets of trees enclosed by dashed lines show genets $A$ to $\mathrm{G}$. Large curved stems are shown by solid lines. The arrows and values indicate the direction and degree of the slope, respectively.

important triggers for layering propagation, heavy snow may not always be necessary. In Ishinomaki (the northernmost population on the Pacific Ocean side), snow does not disappear readily due to the low temperature, which may lead to successful seedling-layering and/or sprout-layering even given the low snow depth.

Kimura et al. (2013) suggested that genetic factors have a more significant effect on clonality than environmental factors, such as snow depth. Kimura et al. (2014) investigated the genetic characteristics of 37 natural populations and suggested that the Ishinomaki $C$. japonica population has its main gene pool on the Pacific Ocean side. However, the sprouts and large curved stem of $C$. japonica observed in Ishinomaki are typical morphological features of $C$. japonica var. radicans. Because all populations have gene pools both on the Pacific Ocean side and the Japan Sea side (Kimura et al., 2014), layering propagation may occur not only in C. japonica, but also in C. japonica var. radicans if environmental factors are stable.

\section{Acknowledgement}

The authors are grateful to Dr. M. Kimura for valuable discussions. We thank R. Katayama and Dr. K. Uchiyama for their assistance in collecting samples and weather data, respectively.

This study was in part supported by a GLocal AGE 2020 Japanese Scholarship program. 


\section{References}

Kimura MK, D Kabeya, T Saito, Y Moriguchi, K Uchiyama, C Migita, Y Chiba and Y Tsumaru (2013) Effects of genetic and environmental factors on clonal reproduction in old-growth natural populations of Cryptomeria japonica. Forest Ecology and Management 304 (2013) 10-19 https://doi.org/10.1016/j.foreco.2013.04.030

Kimura MK, K Uchiyama, K Nakao, Y Moriguchi, L San Jose-Maldia and Y Tsumura (2014) Evidence for cryptic northern refugia in the last glacial period in Cryptomeria japonica. Annals of Botany 114:1687-1700 https://doi.org/10.1093/aob/mcu197

Maeda T (1983) The natural distribution. In: Sakaguchi K, M Iwakawa, N Hashimoto, K Ito, K Hachiya, J Taniguchi, K Imamura, K Shiojima (eds) Everything of sugi (Cryptomeria japonica D. Don). Forest Technical Association, Tokyo. pp. 8-11, 28 (In Japanese)

Moriguchi Y, A Matsumoto, M Saito, Y Tsumura and H Taira (2001) DNA analysis of clonal structure of an old growth, isolated forest of Cryptomeria japonica in a snowy region. Canadian Journal of Forest Research 31: 377-383 https://doi.org/10.1139/x00-177

Moriguchi Y, Hiroyoshi, H Iwata, Tokoku Ujino-Ihara, H Taira and Y Tsumura (2003) Development and characterization of microsatellite markers for Cryptomeria japonica D. Don. Theoretical and Applied Genetics 106: 751 758. https://doi.org/10.1007/s00122-002-1149-0

Ohashi H (2015) Cupressaceae. In: Ohhashi H, Y Kadota, H Murata, K Yonekura, H Kihara (eds) Wild flowers of Japan, Vol, Cycadaceae Cyperaceae. Heibonsha, Tokyo, Japan, P37 (In Japanese)

Taira H (1985) Distribution of Tateyama sugi (Cryptomeria japonica D. Don) in northern part of the Japan Alps. Shinrin Richi, 27: 1-7 (In Japanese)

Taira H (1994) The regeneration system of Tateyama sugi (Cryptomeria japonica). Journal of the Japanese Forest Society 76: 547-552 (In Japanese)

Taira H (2011) Story of large Sugi in Natural Forests. J-FIC, Tokyo, Japan (In Japanese)

Taira H, Y Tsumura, N Tomaru and K Ohba (1997) Regeneration system and genetic diversity of Cryptomeria japonica growing at different altitudes. Canadian Journal of Forest Research 27: 447-452 https://doi.org/10.1139/x97-001

Tani, N, T Takahashi, T Ujino-Ihara, H Iwata, K Yishimura and Y Tsumura, (2004) Development and characteristics of microsatellite markers for sugi (Cryptomeria japonica D. Don) derived from microsatellite-enriched libraries. Annals of Forest Science 61, 569-575. https://doi.org/10.1051/forest:2004052

Tohyama T (1960) On the subdivision of sugi into omote- and ura-type. The bulletin of the shimane agricultural college, 8: 141-149 (In Japanese)

Tsumura Y (2011) Cryptomeria. In: Kole C (eds) Wild crop relatives: Genomics and breeding resources, forest trees. Berlin, Springer, pp 49-64, ISBN 3642160565

Tsumura Y, T Kado, T Takahashi, N Tani, T Ujino-lhara and H Iwata (2007) Genome scan to detect genetic structure and adaptive genes of natural populations of Cryptomeria japonica. Genetics 176: 2393-2403 https://doi.org/10.1534/genetics.107.072652

Tsumura Y, K Yoshimura, N Tomaru and K Ohba (1995) Molecular phylogeny of conifers using RFLP analysis of PCR-amplified specific chloroplast genes. Theoretical and Applied Genetics 91: 1222-1236 https://doi.org/10.1007/bf00220933

Yamazaki T (1995) Cryptomeriaceae. In: Iwatsuki K, T Yamazaki, DE Boufford, H Ohba (eds) Flora of Japan, Vol I, Pteridophyta and Gymnospermae. Kodansha, Tokyo, Japan, P264. https://doi.org/10.2307/1547646

Yasue M, Ogiyama K, Suto S, Tsukahara H, Miyahara F and Ohba K (1987) Geographical differentiation of natural Cryptomeria stands analysed by diterpene hydrocarbon constituents of individual trees. Journal of the Japanese Forest Society 69: 152-156 